\title{
INFLUENCE OF SCHOOLBAG CARRIAGE ON PATTERN CHANGES IN PLANTAR PRESSURE DURING WALKING AMONG FIRST-GRADE SCHOOLCHILDREN
}

\author{
Mario Kasović1, Martin Zvonar², Larisa Gomaz ${ }^{1}$, Filip Bolčević1, and Vincent Anton ${ }^{2}$ \\ ${ }^{1}$ Faculty of Kinesiology, University of Zagreb, Croatia \\ ${ }^{2}$ Faculty of Sports Studies, Masaryk University, Brno, the Czech Republic
}

Original scientific paper
https://doi.org/10.26582/k.50.2.14
UDC: $796.51-053.5$

\begin{abstract}
:
The aim of this study was to determine the influence of schoolbag carriage on pattern changes in plantar pressure during walking among schoolchildren of first grade. The sample consisted of 127 schoolchildren, $48.8 \%$ male $(\mathrm{n}=62)$ and $51.2 \%$ female $(\mathrm{n}=65)$, aged $6.7( \pm 0.5)$ years. The mean schoolbag weight was $4.2 \mathrm{~kg}( \pm 0.7)$, which represented $16.9 \%( \pm 3.9)$ of children's body weight, thus exceeding the upper limit of the recommended $15 \%$ of the body weight and generally affecting their posture. The study has shown the statistically significant influence of the schoolbag on changes in plantar pressure pattern when walking in relation to walking without the schoolbag. Using a $t$-test for large dependent samples and by setting statistical significance at $p \leq .05$, the significant increase was noticed in peak pressure for the forefoot $(p=.000$; $17.1 \%)$, midfoot $(\mathrm{p}=.000 ; 5.7 \%)$ and hindfoot $(\mathrm{p}=.004 ; 3.9 \%)$ as well as in average pressure for the midfoot $(\mathrm{p}=.005 ; 6.2 \%)$. Also, due to the compensatory mechanisms activated while the bag was being carried, the statistically significant increase in the contact surface at the forefoot $(\mathrm{p}=.000 ; 3.6 \%)$ and midfoot $(\mathrm{p}=.000$, $8.8 \%$ ) occurred. Changes in the distribution of pressure between different parts of the foot are a source of potential foot problems which is why the results of this study have a high applicability in the prevention of foot pathology in the future.
\end{abstract}

Key words: school bag, pedobarography, gait biomechanics

\section{Introduction}

Lack of physical activity in children has been recognized by the World Health Organization as one of the primary problems of modern living. Schoolchildren spend most of their time sitting in school benches, which increases static strain on them and significantly reduces the time they spend in physical activity playing. During the entire period of schooling, schoolbags are the main means for the transfer of books and accessories, the transportation of which makes the daily activity of the majority of children (Al-Saleem, et al., 2016). Schoolbag's excessive weight can lead to muscle imbalances during the growth phase and later in life to chronic pain and posture problems (AAOS, 2018).

The scientific community confirms that carrying a schoolbag of inadequate weight is one of the risks to the health and proper growth of the child, which is why optimal schoolbag weight values are recommended to range within $10-15 \%$ of the child's body weight (Bauer \& Freivalds, 2009; Brackley, Stevenson, \& Salinger, 2009; Chow, et al.,
2005; Dockrell, Simms, \& Blake, 2012; van Gent, de Rover, Sing, \& Vet, 2003; Voll \& Klimt, 1977). Research has shown that the weight ratio of schoolbags and the weight of a child within the recommended limits causes a prolonged blood pressure recovery (Hong \& Brueggemann, 2000; Hong, Li, Wong, \& Robinson, 2000) and changes in kinetic, kinematic and electromyographic parameters (Bobet \& Norman, 1984; Chow, et al., 2005), while values that exceed the upper limit of this interval as well as certain types of school bags can cause pressure on the nerves at the tip of the neck, thus leading to muscle spasms as well as neck and shoulder pain (Mao, Brandon, \& Hargens, 2015).

The problem of overweight school bags is gaining more attention of both sports medicine specialists, school leaders, teachers and parents. Approximately $70 \%$ of orthopaedic doctors of the American Academy of Orthopaedic (AAOS) find that heavy schoolbags can be responsible for the development of pain in the lumbar spine and represent a risk of proper foot development (Siambanes, 
Martinez, Butler, \& Haider, 2004; Viry, Creveuil, \& Marcelli, 1999) being dependent also on the path to school, the time children carry their bags, and the surface on which the children are walking. In urban environments, children mostly walk on hard asphalt and concrete surfaces, which is why the load on their feet and entire bodies is uniform providing no proper stimulation of body muscles work that would promote proper development of the feet and overall body posture (Kasović, Zvonar, \& Sebera, 2014).

In elementary school first-graders, the bone and muscle-tendon-ligament system is still in a very sensitive stage of development, due to which an inadequate weight of a school bag can contribute to an increased forward leaning of the torso, reducing lumbar lordosis and kyphosis (Bloom \& WoodhullMcneal, 1987; Mackie \& Legg, 2008; Negrini \& Negrini, 2007; Pascoe, Pascoe, Wang, Shim, \& Kim, 1997; Singh \& Koh, 2009), or causing disorders of static balance in the form of increased sidemovements of the body (Pau \& Pau, 2010), plantar pressure deformations as well as changes in time and spatial walking parameters (Pau, Corona, Leban, \& Pau, 2011; Pau, Mandaresu, Leban, \& Nussbaum, 2015). As a result, plantar pressure strains are a consequence of the changed location of the centre of mass for the body-school bag system (Bloom \& Woodhull-McNeal, 1987; Brackley, et al., 2009; Goh, Thambyah, \& Bose, 1998; Negrini \& Negrini, 2007;).

The aim was to determine the influence of schoolbag carriage on pattern changes in plantar pressure during walking among the schoolchildren of first grade, which can lead to long-term conse- quences to health and quality of life of the children of that age.

\section{Methods}

\section{Participants}

The research was conducted at the Faculty of Sports Studies at Masaryk University in Brno (the Czech Republic). Data collection was conducted in the form of field measurements in five different elementary schools in the city of Brno. The sample consisted of 127 primary schoolchildren, $48.8 \%$ male $(\mathrm{n}=62)$ and $51.2 \%$ female $(\mathrm{n}=65)$, being of $6.7( \pm 0.5)$ years of age, body height $126.6 \mathrm{~cm}( \pm 5.7)$ and body mass $25.6 \mathrm{~kg}( \pm 4.2)$ (Table 1$)$.

Prior to the survey, the participants and their parents were informed of the measurement protocol, potential contribution of the research and possible discomforts during the execution after which they signed a Statement of Consent for Voluntary Participation in Research. The Committee for Scientific Research and Ethics of the Faculty of Sports Studies approved the implementation of the research. During the study, none of the participants had any pathological abnormalities of the feet, acute or chronic injuries or any other illness or condition that could affect walking and measurements. The respondents were asked to include all the school material in the schoolbag that they had brought to school on that day to get information on the actual condition of the children's burden. The average weight of the school bags was $4.2 \mathrm{~kg}( \pm 0.7)$ representing an average of $16.9 \%( \pm 3.9 \%)$ of the participants' average body weight. Participants carried their schoolbags over

Table 1. Descriptive analysis of variables for male and female population separately and for the entire sample

\begin{tabular}{|c|c|c|c|c|c|c|}
\hline & \multicolumn{2}{|c|}{ Boys } & \multicolumn{2}{|c|}{ Girls } & \multicolumn{2}{|c|}{ Total } \\
\hline & MIN-MAX & Mean $\pm S D$ & MIN-MAX & Mean $\pm S D$ & MIN-MAX & Mean \pm SD \\
\hline Age (years) & $6.0-7.0$ & $6.7 \pm 0.4$ & $6.0-7.0$ & $6.6 \pm 0.5$ & $6.0-7.0$ & $6.7 \pm 0.5$ \\
\hline Body height $(\mathrm{cm})$ & $113.6-141.2$ & $126.5 \pm 5.6$ & 110.4-141 & $126.8 \pm 5.9$ & $110.4-141.2$ & $126.6 \pm 5.7$ \\
\hline Body weight (kg) & $17.7-31.3$ & $24.8 \pm 3$ & $17.1-40.5$ & $25.6 \pm 5$ & $17.1-40.5$ & $25.6 \pm 4.2$ \\
\hline
\end{tabular}

Table 2. Bag weight and the percentage that the bag represents for the total population

\begin{tabular}{lcc}
\hline & MIN-MAX & Mean \pm SD \\
\hline Bag weight $(\mathrm{kg})$ & $2.3-6.5$ & $4.2 \pm 0.7$ \\
Bag weight $(\% \mathrm{TM})$ & $8.9-29.3$ & $16.9 \pm 3.9$ \\
& & \\
Bag weight $(\% \mathrm{TM})$ & $\mathrm{N}$ & $\%$ \\
\hline$<10 \% \mathrm{TM}$ & 4 & 3.1 \\
$>10 \% \mathrm{TM}$ & 123 & 96.9 \\
$>15 \% \mathrm{TM}$ & 88 & 69.3 \\
$>20 \% \mathrm{TM}$ & 25 & 19.7 \\
$>25 \% \mathrm{TM}$ & 4 & 3.1 \\
\hline
\end{tabular}

both shoulders. As many as $69.3 \%$ of respondents carried a bag which weight made up more than the recommended $15 \%$ of their body weight (Table 2 ). Measurements were carried out at about the same time of day in the morning hours.

\section{Method of measurement and data processing}

For the purposes of measuring, collecting and processing of data, pedobarographic platform Emed-xl was used; its dimensions were $152 \times 50 \times 1.8$ $\mathrm{cm}$, made up of 25344 sensors working at $100 \mathrm{~Hz}$ frequency. Also, the Emed software package from Novel, Germany, was used. 
Before the measurement, the student's body weight, body height without shoes and schoolbag weight were measured. Dynamic measurements were carried out during a spontaneous and natural walk through a measuring polygon first without a schoolbag and then with it. The students had the opportunity to take several attempts to move across the measurement path until at least three natural and proper steps were taken for each foot.

Based on evidence in the recent scientific literature, three basic variables were selected: peak pressure $(\mathrm{kPa})$, average pressure $(\mathrm{kPa})$ and contact surface $\left(\mathrm{cm}^{2}\right)$ for the forefoot, midfoot and hindfoot. The peak pressure for each foot section represents the highest value of plantar pressure measured by the individual sensor on that part of the contact surface, while the average pressure for each foot section represents the mean value of plantar pressure obtained by measuring each sensor on that part of the contact surface (Pau, et al., 2015). The contact surface for the three parts of the foot was calculated according to the description of Cavanagh and Rodgers (1987). All signals were processed as the arithmetic mean of three attempts for each variable under each condition.

\section{Statistical analysis of data}

The collected measurements were recorded and processed using the software package Statistica 13.0 (StatSoft, Tulsa, USA), licensed to the Faculty of Kinesiology, University of Zagreb, Croatia. Descriptive parameters were calculated first.

The differences between the initial and final measurements were verified by $t$-test for large dependent samples. The level of significance was set to value $p \leq .05$.

\section{Results}

The results obtained (Table 3) indicated that for the condition with a schoolbag, compared to the condition without a schoolbag, there was a statistically significant increase in peak pressure values for the forefoot $(\mathrm{p}=.000 ; 17.1 \%)$, midfoot $(\mathrm{p}=.000 ; 5.7 \%)$ and hindfoot $(\mathrm{p}=.004 ; 3.9 \%)$. Also for the condition with a schoolbag, there was a statistically significant increase in average pressure for the midfoot $(\mathrm{p}=.005 ; 6.2 \%)$ compared to the one without the schoolbag, while the change of the conditions did not significantly affect the average pressure for the forefoot $(\mathrm{p}=875 ;-0.3 \%)$ or the hindfoot $(\mathrm{p}=.125 ;-1.4 \%)$. A statistically significant effect of the condition with a schoolbag was noticed in the increase in the contact surface for the forefoot $(\mathrm{p}=.000 ; 3.6 \%)$ and the midfoot $(\mathrm{p}=$ $.000 ; 8.8 \%$ ), while the change in conditions did not significantly affect the change in the contact surface for the hindfoot $(\mathrm{p}=.617 ; 0.3 \%)$.

\section{Discussion and conclusion}

Schoolbags represent the most widespread cargo-carrying method for children and adolescents (Forjuoh, Lane, \& Schuchmann, 2003; Goodgold \& Nielsen, 2003; Pau \& Pau, 2010; Whittfield, Legg, $\&$ Hedderley, 2005) and if they are overweight, they can cause pain and injuries in children (Bauer \& Freivalds, 2009; Talbott, Bhattacharya, Davis, Shukla, \& Levin, 2009; Whittfield, et al., 2005). In order to reduce the risk to the health of the child, Hong et al. (2000) and Forjuoh et al. (2003) recommend carrying a school bag whose weight makes up to $15 \%$ of the child's body weight. Descriptive analysis showed that for the participants in

Table 3. Plantar pressure values and the contact surface for the forefoot, midfoot and hindfoot during walking for the total population. The values are expressed as Mean $\pm S D$; p-values are determined for the differences between the conditions without and with the school bag and the symbol * denotes a significant influence

\begin{tabular}{|c|c|c|c|c|}
\hline & $\begin{array}{c}\text { Without } \\
\text { a school bag }\end{array}$ & $\begin{array}{c}\text { With } \\
\text { a school bag }\end{array}$ & Change (\%) & $\begin{array}{c}\text { The influence of } \\
\text { school bag } p \text { values }\end{array}$ \\
\hline \multicolumn{5}{|l|}{ Peak pressure } \\
\hline Forefoot (kPa) & $192.1 \pm 71.2$ & $225.0 \pm 76.5$ & $17.1 \%$ & 0.000000 * \\
\hline Midfoot (kPa) & $111.2 \pm 17.9$ & $117.5 \pm 25.7$ & $5.7 \%$ & 0.000000 * \\
\hline Hindfoot (kPa) & $344.1 \pm 144.9$ & $357.5 \pm 141.5$ & $3.9 \%$ & 0.004467 * \\
\hline \multicolumn{5}{|c|}{ Average pressure } \\
\hline Forefoot (kPa) & $346.9 \pm 191.6$ & $345.9 \pm 187.2$ & $-0.3 \%$ & 0.874992 \\
\hline Midfoot (kPa) & $332.9 \pm 192.5$ & $353.7 \pm 200.0$ & $6.2 \%$ & 0.004575 * \\
\hline Hindfoot (kPa) & $138.7 \pm 35.0$ & $136.7 \pm 26.7$ & $-1.4 \%$ & 0.124740 \\
\hline \multicolumn{5}{|c|}{ Contact surface } \\
\hline Forefoot $\left(\mathrm{cm}^{2}\right)$ & $129.2 \pm 24.9$ & $133.9 \pm 27.7$ & $3.6 \%$ & 0.000067 * \\
\hline Midfoot $\left(\mathrm{cm}^{2}\right)$ & $97.8 \pm 54.0$ & $106.4 \pm 49.8$ & $8.8 \%$ & 0.000011 * \\
\hline Hindfoot $\left(\mathrm{cm}^{2}\right)$ & $118.8 \pm 20.0$ & $119.2 \pm 15.9$ & $0.3 \%$ & 0.616729 \\
\hline
\end{tabular}


a)

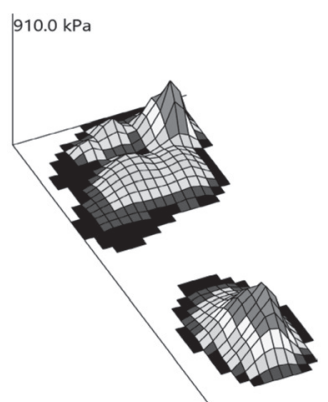

b)

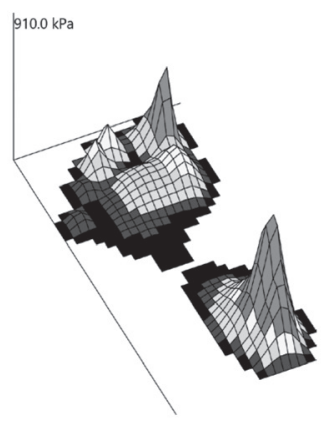

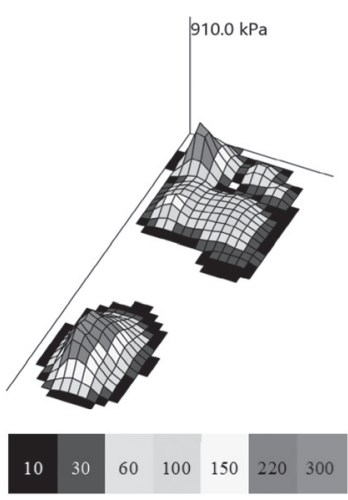

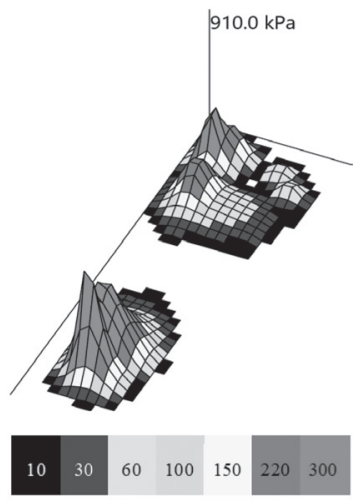

Figure 1. Distribution of plantar pressure on the left and right leg in a condition without (a) and with a schoolbag (b) whose weight makes up $29.3 \%$ of the body weight. When the weight of the schoolbag exceeds the upper limit of the $15 \%$ of the body weight, plantar pressure changes occur. In (a) we can see that there is an extremely high value of the plantar pressure $(300$ $\mathrm{kPa}$ ), for the forefoot and the hindfoot, without a schoolbag. In (b) those plantar pressure values increase after adding the schoolbag and those values are higher for the total foot, especially for the forefoot and the hindfoot.

the present study the bag was overly burdensome because its average weight exceeded the upper limit of the recommended value. The data obtained are in line with the research conducted on the problem of inadequate weight of children's schoolbags in the world (Al-Saleem, et al., 2016; Goodgold, et al., 2003; Mohan, Singh, \& Quddus, 2007; Negrini, Carabalona, \& Sibila, 1999; Nor Azlin, Asfarina, \& Wan Chi, 2010; Pascoe, et al., 1997; Viry, et al., 1999), demonstrating that carrying an overweight schoolbag represented one of the risks to health and proper growth of the child (Dockrell, 2012).

This research has shown that walking with a schoolbag changes the plantar pressure pattern in children in relation to walking without it.

The distribution of plantar pressure changes when the condition changes in the form of the increased peak pressure for all the three parts of the foot, the average pressure for the midfoot and the contact surface for the forefoot and the midfoot, which is in accordance with previous research. According to Connolly et al. (2008), the walking pattern changes when the schoolchildren are
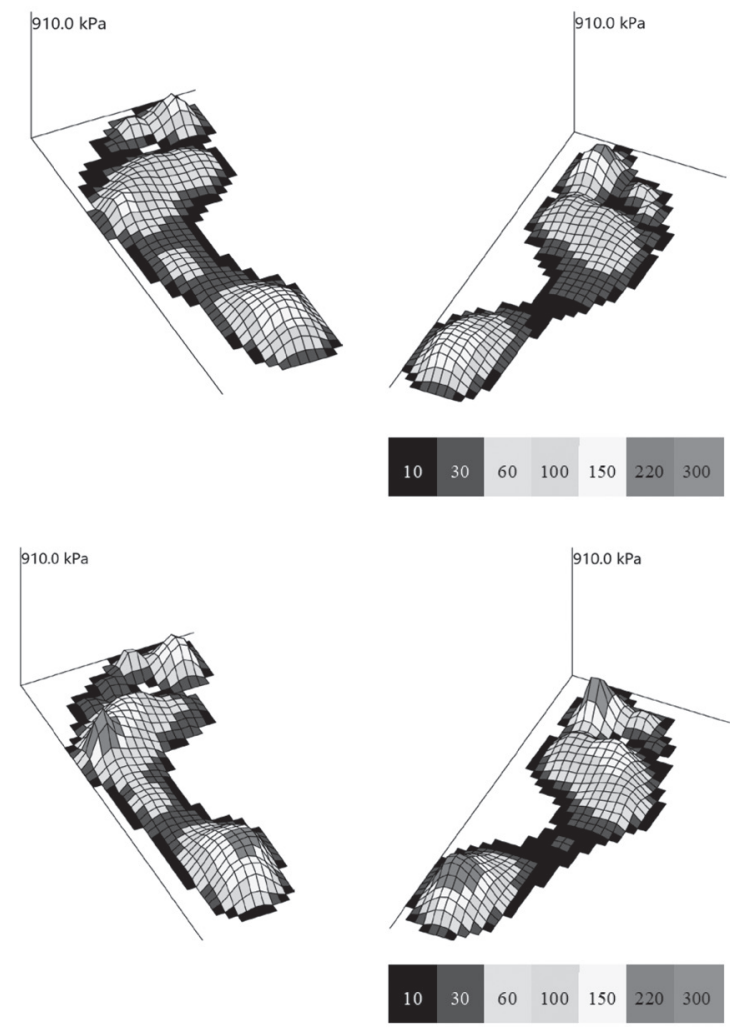

Figure 2. Distribution of plantar pressure of the left and right leg in the condition without (a) and with the schoolbag (b) whose weight makes up $14 \%$ of the body weight. When the weight of the schoolbag does not exceed recommended values of $15 \%$ of the body weight, then the values of the plantar pressure are not high as presented in Figure 1. In (a) values of plantar pressure in condition without a schoolbag are around $150 \mathrm{kPa}$. By adding the schoolbag in (b) we can see that those values increase, for the forefoot and the hindfoot, but they are still around $220 \mathrm{kPa}$, which is a big difference if we compare it with the values in Figure 1.

overly burdened with a load that makes over $15 \%$ of their body weight. Pau et al. (2011) found that by increasing the load to $20-30 \%$ of the body weight, plantar pressure in the forefoot was significantly increased. This pattern of walking due to carrying the school bag is characterized by an increased forward trunk lean as a reaction to the changed position of the centre of mass of the body-school bag system (Bloom \& Woodhull-McNeal, 1987, Brackley, et al., 2009; Goh, et al., 1998, Negrini \& Negrini, 2007). To reduce the resulting instability or mechanical stress on the musculoskeletal system, children use compensatory mechanisms that cause changes in time-spatial walking parameters (Singh $\&$ Koh, 2009). Carrying the schoolbag increases contact surface of the forefoot and the midfoot, as a result of compensatory mechanisms like the forward trunk lean, and the force acting on that surface. The consequence of adding the schoolbag is an increase to the ratio of the force and the surface of the foot on which it acts, which is then manifested as an increase in peak pressure. As a result of the weight ratio of the school bag and the body 
weight of the child deviating from the intervals of the recommended values, excessive peak pressure is reported (Figure 1), as well as changes in the pressure distribution in comparison with the distribution of pressure at the appropriate proportions of the weight of the bag and the child (1 and Figure 2).

Excessive peak pressure values and changes in the ratio of the load distribution between the different parts of the foot are a source of potential problems with the foot, from blisters and thickening of the skin, to a serious damage to the metatarsal bone or stress fracture (Knapik, Harman, \& Reynolds, 1996). In addition, it is assumed that mechanical overload of the foot, which results in a change in the plantar pressure distribution, especially in the midfoot, may contribute to the ocurrence of plantar fasciitis (Wearing, Smeathers, Urry, Henning, \&
Hills, 2006). These phenomena indicate inadequate development of the child's foot, which is why it does not absorb the default load and, as a consequence of this, plantar fasciitis and feet as a whole do not function adequately. Potentially, this pattern may be a mechanism for the formation of flatfeet in children, plantar fasciitis, and other foot pathologies in the future.

The conducted research and its results have a high practical value and applicability in early detection of potential problems for the locomotor system of children in their highly sensitive stage of growth. Understanding and early detection of changes and deformations will enable timely preventive actions which will prevent negative effects on health and quality of life.

\section{References}

Al-Saleem, S.A., Ali, A., Ali, S.I., Alshamrani, A.A., Almulhem, A.M., \& Al-Hashem, H.M. (2016). A study of school bag weight and back pain among primary school children in Al-Ahsa, Saudia Arabia. Epidemiology (Sunnyvale), 6(1), 222. doi: 10.4172/2161-1165.1000222

American Academy of Orthopaedic Surgeons (AAOS). (2018). Backpack safety. Retrieved from: https://orthoinfo.aaos. org/en/staying-healthy/backpack-safety/

Bauer, D.H., \& Freivalds, A. (2009). Backpack load limit recommendation for middle school students based on physiological and psychophysical measurements. Work, 32(3), 339-350. doi: 10.3233/WOR-2009-0832

Bloom, D., \& Woodhull-McNeal, A.P. (1987). Postural adjustment while standing with two types of loaded backpack. Ergonomics, 30(10), 1425-1430. doi.org/10.1080/00140138708966036

Bobet, J., \& Norman, R.W. (1984). Effects of load placement on back muscle activity in load carriage. European Journal of Applied Physiology and Occupational Physiology, 53(1), 71-75.

Brackley, H.M., Stevenson, J.M., \& Selinger, J.C. (2009). Effect of backpack load placement on posture and spinal curvature in prepubescent children. Work, 32(3), 351-360. doi: 10.3233/WOR-2009-0833.

Cavanagh, P.R., \& Rodgers, M.M. (1987). The arch index: A useful measure from footprints. Journal of Biomechanics, 20(5), 547-551.

Chow, D.W., Kwok, M.L., Au-Yang, A.C., Holmes, A.D., Cheng, J.C., Yao, F.Y., \& Wong, M.S. (2005). The effects of backpack load on the gait of normal adolescent girl. Ergonomics, 48(6), 642-656. doi.org/10.1080/00140130500070921

Connolly, B.H., Cook, B., Hunter, S., Laughter, M., Mills, A., Nordtvedt, N., \& Bush, A. (2008). Effects of backpack carriage on gait parameters in children. Pediatric Physical Therapy, 20(4), 347-355. doi: 10.1097/ PEP.0b013e31818a0f8f.

Dockrell, S., Simms, C., \& Blake, C. (2013). Schoolbag weight limit: Can it be defined? Journal of School Health, 83(5), 368-377. doi: 10.1111/josh.12040.

Forjouh, S.N., Lane, B.L., \& Schuchmann, J.A. (2003). Percentage of body weight carried by students in their school backpaks. American Journal of Physical Medicine and Rehabilitation, 82(4), 261-266. doi: 10.1097/01. PHM.0000057227.35210.50

Goh, J.H., Thambyah, A., \& Bose, K. (1998). Effects of varying backpack loads on peak forces in the lumbosacral spine during walking. Clinical Biomechanics, 13(Suppl. 1), 26-31.

Goodgold, S.A., \& Nielsen, D. (2003). Effectiveness of a school-based backpack health promotion program: Backpack intelligence. Work, 21(2), 113-123.

Hong, Y., \& Brueggemann, G.P. (2000). Changes in gait patterns in 10-year-old boys with increasing loads when walking on a treadmill. Gait Posture, 11(3), 254-259.

Hong, Y., Li, J.X., Wong, A.S., \& Robinson, P.D. (2000). Effects of load carriage on heart rate, blood pressure and energy expenditure in children. Ergonomics, 43(6), 717-727. doi: 10.1080/001401300404698

Kasović, M., Zvonar, M., \& Sebera, M. (2014). Influence of the mass of a school bag on a child's health. Croatian Sports Medicine Journal, 29(2), 84-90.

Knapik, J., Harman, E., \& Reynolds, K. (1996). Load carriage using packs: A review of physiological, biomechanical and medical aspects. Applied Ergonomics, 27(3), 207-216. 
Mackie, H.W., \& Legg, S.J. (2008). Postural and subjective responses to realistic schoolbag carriage. Ergonomics, 51(2), 217-231. doi: 10.1080/00140130701565588

Mao, C., Brandon, R.M., \& Hargens, A.R. (2015). Shoulder skin and muscle hemodynamics during backpack carriage. Applied Ergonomics, 51, 80-84. doi: 10.1016/j.apergo.2015.04.006

Mohan, M., Singh, U., \& Quddus, N. (2007). Effects of backpack loading on cervcial and shoulder posture in Indian school children. Indian Journal of Physiotherapy and Occupational Therapy, 1, 1-9.

Negrini, S., Carabalona, R., \& Sibila, P. (1999). Backpack as a daily load for schoolchildren. Lancet, 354(9194), 1974. doi: 10.1016/S0140-6736(99)04520-1

Negrini, S., \& Negrini, A. (2007). Postural effects of symmetrical and asymmetrical loads on the spines of schoolchildren. Scoliosis, 2, 8. doi.org/10.1186/1748-7161-2-8

Nor Azlin, M.N., Asfarina, Z., \& Wan Chee, L. (2010). Schoolbag weight, its content, and incidence of back pain in different medium primary schools in Kuala Lumpur. Malaysian Journal of Medicine and Health Sciences, 6(2), 59-64.

Pascoe, D.D., Pascoe, D.E., Wang, Y.T., Shim, D.M., \& Kim, C.K. (1997). Influence of carrying book bags on gait cycle and posture of youths. Ergonomics, 40(6), 631-641. doi: 10.1080/001401397187928

Pau, M., Corona, F., Leban, B., \& Pau, M. (2011). Effects of backpack carriage on foot-ground relationship in children during upright stance. Gait and Posture, 33(2), 195-199. doi: 10.1016/j.gaitpost.2010.10.096

Pau, M., Mandaresu, S., Leban, B., \& Nussbaum, A.M. (2015). Short-term effects of backpack carriage on plantar pressure and gait in schoolchildren. Journal of Electromyography and Kinesiology, 25(2), 406-412. doi. org/10.1016/j.jelekin.2014.11.006

Pau, M., \& Pau, M. (2010). Postural sway modifications induced by backpack carriage in primary school children: A case study in Italy. Ergonomics, 53(7), 872-881. doi: 10.1080/00140139.2010.489965.

Siambanes, D., Martinez, J.W., Butler, E.W., \& Haider, T. (2004). Influence of school backpacks on adolescent back pain. Journal of Pediatric Orthopaedics, 24(2), 211-217.

Singh, T., \& Koh, M. (2009). Effects of backpack load position on spatiotemporal parameters and trunk forward lean. Gait and Posture, 29(1), 49-53. doi: 10.1016/j.gaitpost.2008.06.006

Talbott, R.N., Bhattacharya, A., Davis, G.K., Shukla, R., \& Levin, L. (2009). School backpacks: It's more than just a weight problem. Work, 34(4), 481-494. doi: 10.3233/WOR-2009-0949.

Van Gent, C., Dols, J.J.C.M., de Rover, C.M., Sing, R.A.H., \& de Vet, H.C.V. (2003). The weight of schoolbags and the occurrence of neck, shoulder and back pain in young adolescents. Spine, 28(9), 916-921. doi: 10.1097/01. BRS.0000058721.69053.EC

Viry, P., Creveuil, C., \& Marcelli, C. (1999). Nonspecific back pain in children. A search for associated factors in 14-year-old schoolchildren. Revue du Rhumatisme, 66(7-9), 381-388.

Voll, H.J., \& Klimnt, F. (1977). On strain in children caused by carrying schoolbags. Offentliche Gesundheitswesen, 39(7), 369-378.

Wearing, S.C., Smeathers, J.E., Urry, S.R., Henning, E.M., \& Hills, A.P. (2006). The pathomechanics of plantar fasciitis. Sports Medicine, 36(7), 585-611.

Whittfield, J., Legg, S.J., \& Hedderley, D.I. (2005). Schoolbag weight and musculoskeletal symptoms in New Zealand secondary schools. Applied Ergonomics, 36(2), 193-198.

Submitted: September 17, 2018

Accepted: November 30, 2018

Published Online First: December 10, 2018

Correspondence to:

Mario Kasović, Ph.D.

Faculty of Kinesiology, University of Zagreb, Croatia

Email: mario.kasovic@kif.hr 